Author's post-print: I. Indacoechea-Vega, P. Pascual-Muñoz, D. Castro-Fresno, M.A. Calzada-Pérez. "Experimental characterization and performance evaluation of geothermal grouting materials subjected to heating-cooling cycles". Construction and Building Materials 98 (2015), 583-592. ISSN: 950-0618.

\title{
Experimental characterization and performance evaluation of geothermal grouting materials subjected to heating-cooling cycles
}

\author{
I. Indacoechea-Vega ${ }^{a}$, P. Pascual-Muñoz ${ }^{\text {b }}$, D. Castro-Fresno ${ }^{c}$, M.A. Calzada-Pérez ${ }^{d}$
}

a GITECO Research group, Universidad de Cantabria, 39005, Santander, Spain. Email: indacoecheai@unican.es

b GITECO Research group, Universidad de Cantabria, 39005, Santander, Spain. Email: pascualmp@unican.es Tel: (+34) 9422039 43; Fax: (+34) 942201703

c GITECO Research group, Universidad de Cantabria, 39005, Santander, Spain. Email: castrod@unican.es d GCS Research group, Universidad de Cantabria, 39005, Santander, Spain. Email: miguel.calzada@unican.es

\section{Abstract}

In recent years, the increasing rise in environmental awareness among energy consumers has led to an increasing use of renewable energies such as the geothermal energy. An important role in the efficient exploitation of the geothermal resource is played by the grouting material placed in the borehole between the pipes and the ground. Actually, the use of proper grouts is essential to provide an effective heat transfer between the ground and the heat carrier fluid in the pipes, and also to comply with the mechanical and environmental demands. However, when it comes to the construction of the GHP installations, the grout is especially required to be easy to work with (workable) and for this reason more water than required is sometimes added. In order to assess the suitability of grouting materials with significant water/solid ratios, the thermal conductivity, mechanical strength and permeability of five different grouts and grout-pipe specimens were measured for their laboratory characterization. In addition, the grouts were subjected to heating and cooling cycles to evaluate their durability with time in terms of the potential degradation of the materials and the loss of quality of the grout-pipe interface. According to the results obtained, the grouts here tested are appropriate for most of the geothermal heat pump installations, especially for those with low to medium ground thermal properties.

Keywords: geothermal energy, grouting material, workability, thermal conductivity, permeability, durability. 


\section{Introduction and background}

The environmental impact caused by the extended use of the energy for lighting, heating and cooling purposes [1] is leading to the gradual increase of consumer attitude towards the mindful use of the natural resources [2] and the efficient consumption of alternative energies. Accordingly, the use of vertical shallow geothermal energy systems or ground source heat pumps (GSHP) is emerging. This technology offers a renewable, clean and efficient source of energy. However, its installation is slightly more difficult as compared to more conventional systems and therefore, more expensive [3].

In this context, the optimum design of a vertical shallow geothermal closed-loop heat exchanger that shortens the return of investment period, requires the accurate analysis of all the components involved in the process through which heat is exchanged with the earth. Among these components (Figure 1), the grouting material located between the pipe and the ground is very important due to its crucial functions: allow the borehole stability, make possible an efficient heat transfer between the pipe and the ground and provide a hydraulic barrier that avoids the pollution of the aquifers if leaks are present. Therefore, a suitable grouting material should satisfy the following conditions: (1) to possess a very low hydraulic conductivity; (2) to provide a high thermal conductivity; (3) to guarantee a good coupling pipe-grout that avoids harmful debonding effects [4]; and (4) to possess proper mechanical properties that protects the heat exchange system. However, some of these conditions are sometimes sacrificed for the sake of the grout's workability. Thus, when it comes to the construction of the GSHP installation a liquid enough grout is sought so that it can be easily injected within the borehole. 


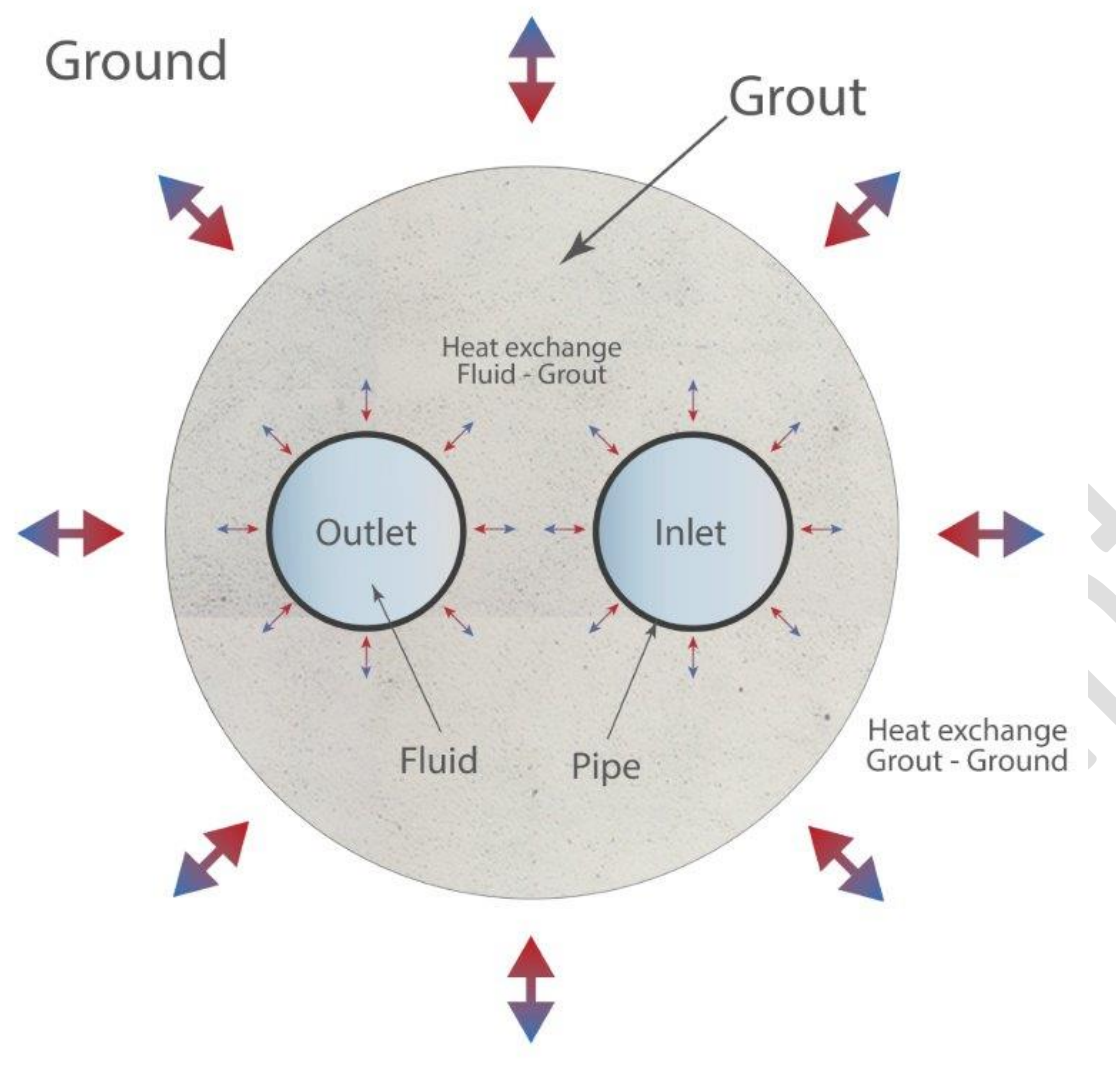

Fig. 1 - Main components of a typical vertical shallow geothermal closed-loop heat exchanger.

Grouting materials for GSHP purposes are mainly divided in two groups: bentonite-based grouts, in which the bentonite is the main component; and cement-based grouts, in which the cement is the prevailing component. The addition of bentonite to cement-based grouts is very common to improve the rheological properties of the resulting mixture.

As geothermal grout, the bentonite offers an easily placed, flexible and very low permeability sealing. On the other hand, its low thermal conductivity and volumetric instability lead to an adverse decrease of the GSHP efficiency. In order to enhance its properties, several authors have analysed the addition of other filling materials [5,6]. Thus, Smith and Perry [7] tested several bentonite-to-sand gradations and analysed the influence of this variable on the performance of real installations. Similarly, Lee et al. [8] tested seven different type of bentonites and compared the values of thermal conductivity and viscosity obtained when different percentages of silica sand and graphite were added. The graphite was proved to bring 
about higher conductivities. More recently, Delaleux et al. [9] evaluated the thermal performance of bentonite-graphite composites elaborated with different forms of graphite. Very high values of thermal conductivity were achieved (up to $5 \mathrm{~W} / \mathrm{m} \cdot \mathrm{K}$ ) for low graphite contents. However, a clear dependency between this parameter and the water content was detected. On the other hand, Erol and François $[10,11]$ carried out a characterization of bentonite-based grouts enhanced with natural-flake graphite among other forms. Results demonstrated that a $5 \%$ graphite addition is enough to highly influence the thermal conductivity of the grout as well as a cost-effective solution.

Concerning cement-based grouts, it is more than remarkable the research work carried out by Allan et al. [12-18]. In terms of thermal performance, the addition of silica sands to neat cements was largely studied by the authors. An optimum grout that met the balance between the required properties, economics and ease of use was chosen for further tests. Theoretical values of required borehole length were calculated by the authors when this grout was used, giving arise reductions of up to $22-37 \%$ depending on soil type and borehole diameter.

Permeability tests were also carried out on the grout to evaluate its sealing performance. Results showed that hydraulic conductivity of the grout itself was very low but increased flow occurred when pipes were incorporated within the test specimen. This was attributed to an existing pathway at the grout-pipe interface and accordingly, an imperfect physical bonding between grouts and pipes was assumed. Therefore, the mechanical bond strength between both components was measured by means of push out tests in which higher loads were necessary to push the pipe inserted in the cement-sand grout as compared to the pipe inserted in neat cement grout. The effect of temperature was also evaluated and results showed a distortion of the micro-annuli at the grout-pipe interface due to the different thermal expansion coefficients of the pipe and the grout. Taking advantage of the previous work, a numerical model was developed that allowed the authors to determine that a total debonding produces a $66 \%$ reduction of the overall heat transfer coefficient [19]. More recently, Berndt [21] and Borinaga et al. [20] studied the addition of steel fibres and recycled materials such as steel 
slags, respectively.

But apart from possessing suitable thermal hydraulic and mechanical properties, a grouting material should be capable of keeping those properties along its service life. Only a limited number of authors have dealt with this issue. In this sense, permeability of cementitious groutpipe specimens subjected to thermal cycles was evaluated by Allan and Philippacopoulos $[13,14]$ and compared to neat cements' behaviour. Small increase of the permeability occurred after cycles but remained of the same order. In contrast, neat cement grouts cracked after the test. The effect of thermal cycles on the hydraulic conductivity of cementitious grout-pipe specimens was also analysed by Park et al. [22]. Results showed no significant change.

According to the background exposed above, the main objectives of this paper are the following: characterize and compare mechanical, thermal and hydraulic properties of five different grouting materials with a high-level workability due to an excess of mixing water; and evaluate the durability of these grouts when they are exposed to heating-cooling cycles that represent the temperatures to which the grout is mostly exposed along its lifetime.

\section{Research Methodology}

\section{Materials and characterization tests}

Five different grouting materials for geothermal purposes were considered for this study. Proportions of these mixtures are shown in Table 1. Four of them consisted of ordinary Portland cement, bentonite, and silica sand and/or graphite as the necessary conductive filler. High water/solid ratios provide these grouts a great workability. The fifth one is a silica-sand based grout with bentonite. 
Table 1 - Properties of the grouting materials according to the characterization tests.

\begin{tabular}{cccccc}
\hline \hline GROUT & G1 & G2 & G3 & G4 & G5 \\
\hline \hline Cement (\%) & 49 & 36 & 35 & 8 & 0 \\
Bentonite (\%) & 4 & 6 & 15 & 18 & 12 \\
Sand (\%) & 18 & 3 & 14 & 38 & 55 \\
Graphite (\%) & 0 & 11 & 3 & 0 & 0 \\
Water (\%) & 30 & 44 & 33 & 36 & 33 \\
\hline water/solid (kg/kg) $^{\text {Fresh density }}$ & 0.40 & 0.80 & 0.50 & 0.60 & 0.50 \\
MF Viscosity & $400 \mathrm{~kg} / \mathrm{m}^{3}$ & $1367 \mathrm{~kg} / \mathrm{m}^{3}$ & $1658 \mathrm{~kg} / \mathrm{m}^{3}$ & $1661 \mathrm{~kg} / \mathrm{m}^{3}$ & $1697 \mathrm{~kg} / \mathrm{m}^{3}$ \\
Hardened density & $1412 \mathrm{~kg} / \mathrm{m}^{3}$ & $832 \mathrm{~kg} / \mathrm{m}^{3}$ & $1240 \mathrm{~kg} / \mathrm{m}^{3}$ & $1245 \mathrm{~kg} / \mathrm{m}^{3}$ & $1317 \mathrm{~kg} / \mathrm{m}^{3}$ \\
Water absorption $^{\text {b }}$ & $30 \%$ & $65 \%$ & $40 \%$ & $40 \%$ & - \\
Accessible porosity $^{\mathbf{b}}$ & $42 \%$ & $54 \%$ & $49 \%$ & $50 \%$ & - \\
Bleeding & $3 \%$ & $<1 \%$ & $<1 \%$ & $<2 \%$ & $<1 \%$ \\
\hline \hline
\end{tabular}

a Hardened density of G5 was calculated based on components (sand and bentonite) proportions and densities.

b Water absorption and Accessible porosity of G5 could not be calculated due to the grout poor consistency.

Different characterization tests were carried out. Thus, fresh and hardened density, wateraccessible porosity, Marsh viscosity and bleeding were determined for the five grouting materials. The bulk density of the fresh specimens was determined according to the standard UNE-EN 1015-6 [24] while the dry bulk density and the water-accessible porosity of the hardened grouts were measured in agreement with the UNE-EN 1015-10:2000/A1 [25].

The plastic viscosity of the grouts was determined by using the Marsh Funnel as defined in ASTM D6910/D6910M - 09 [26]. According to this standard, the grout is poured into the funnel and then allowed to flow into a graduated cup. The Marsh Funnel viscosity (MFV) is measured as the time spent for the grout to fill a volume of $946 \mathrm{ml}$. Finally, bleeding of tested grouts was measured following the procedure given in ASTM C940-10a [27], according to which an 800 $\mathrm{ml}$ quantity of freshly mixed grout was poured into a $1000 \mathrm{ml}$ glass graduated cylinder and covered to prevent evaporation. The heights of grout and any bleed water were read after 3 hours.

Values obtained from all these characterization tests are presented in Table 1. As it can be 
seen, hardened density of $\mathrm{G} 2$ is strongly affected by the water dosage required for its manufacturing. In this sense, Figures 2 and 3 clearly show the effect of this water dosage (in volume and mass, respectively) on the resulting hardened density and the accessible porosity of the tested grouts. Results confirm the well-known influence of the amount of mixing water on the porosity of the grouts and mortars. On the other hand, high values of MF viscosity were detected in G5. Anyway, the grout was functional enough as not to be discarded for the following tests. Based on all this information, all the grouts previously considered were assumed to be suitable for the durability tests.

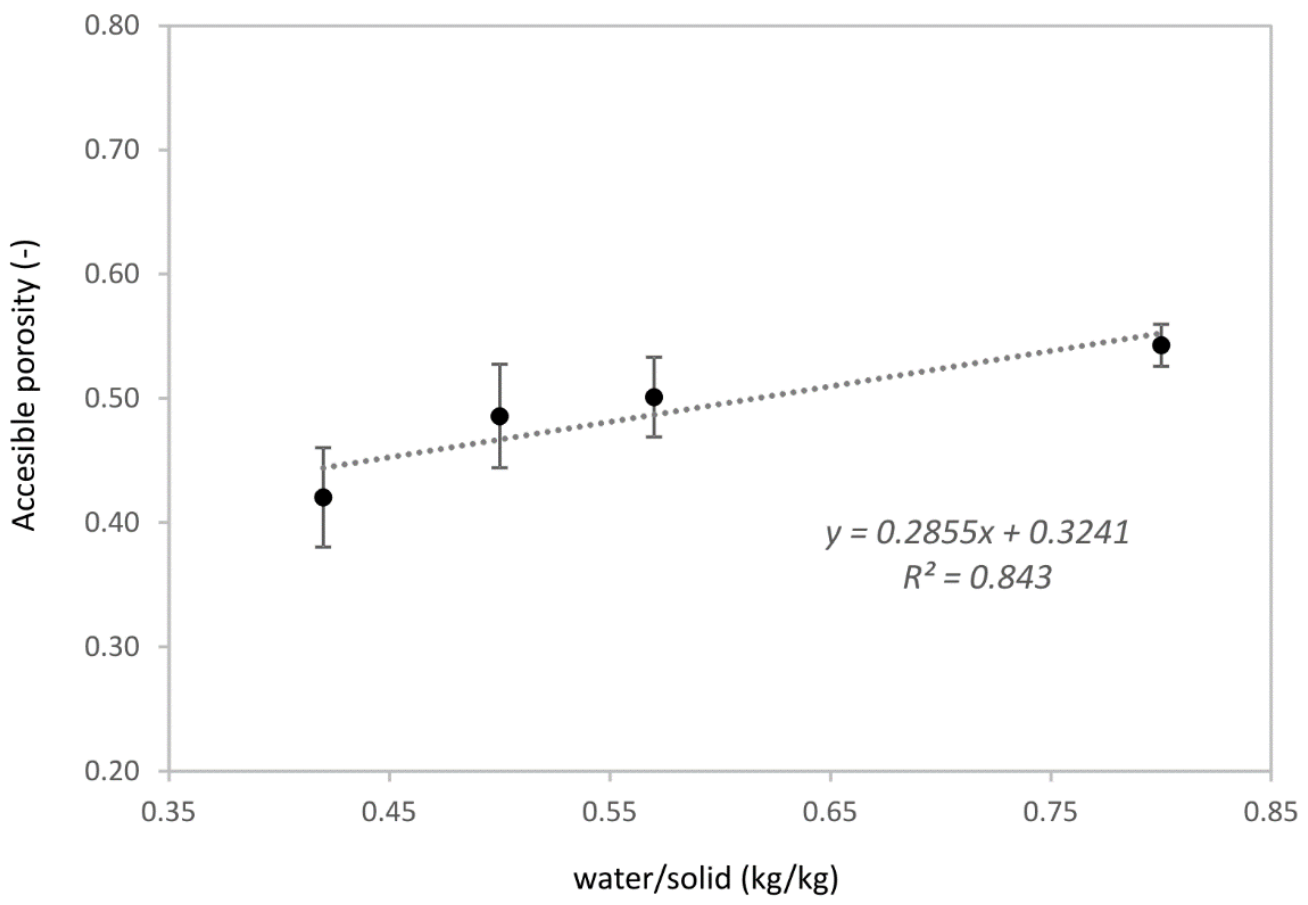

Fig. 2 - Influence of the water/solid ratio on the accessible porosity of the grouts. 


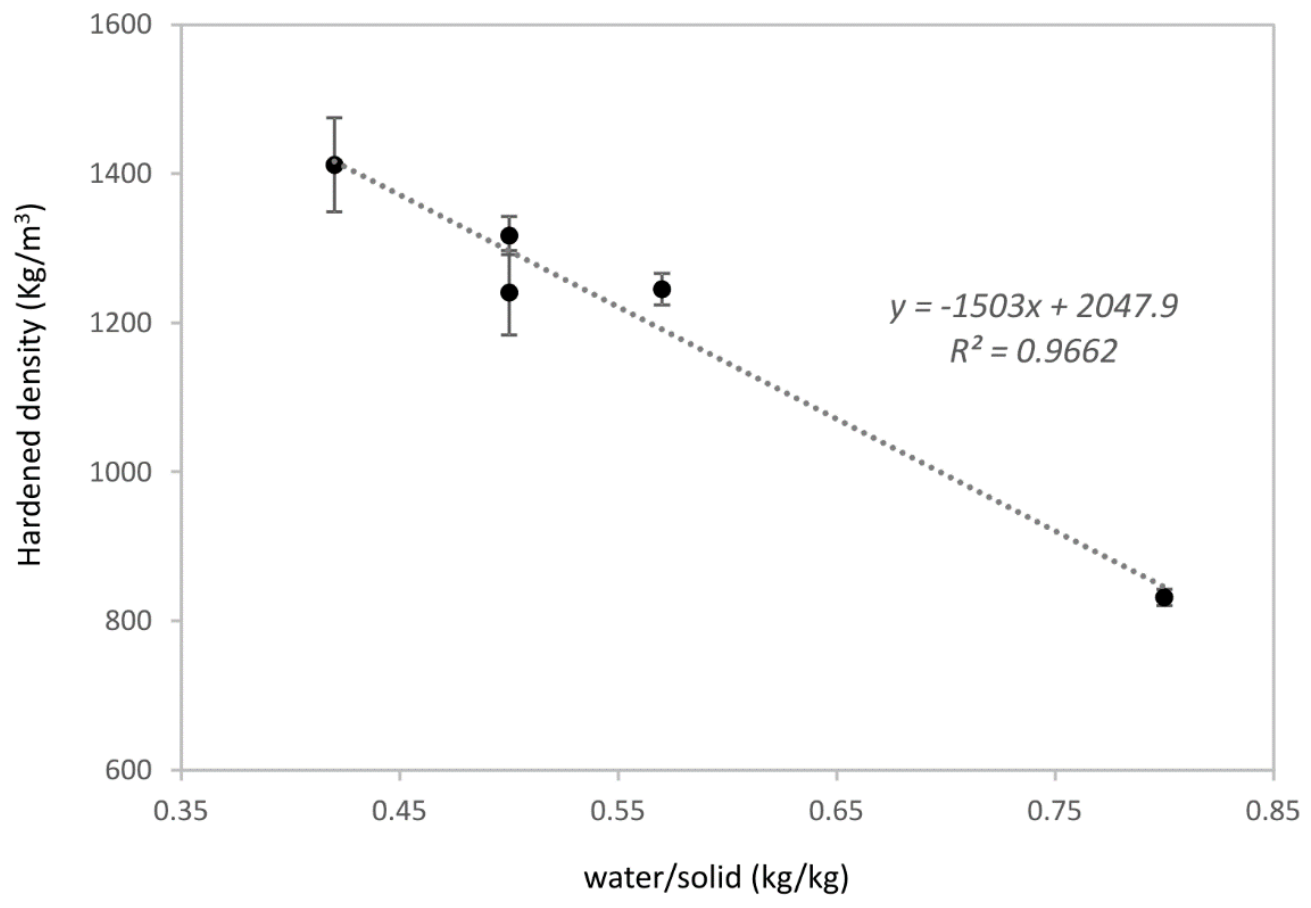

Fig. 3 - Influence of the mixing water on the hardened density of the grouts.

\section{Experimental set-up for durability analysis}

A $750 \mathrm{~W}$ mortar mixer with variable speed was used in the laboratory to fabricate the grout specimens used for the durability tests. Fresh samples were cured under ambient laboratory conditions until molds could be removed. From then, samples were submerged in water at 20 ${ }^{\circ} \mathrm{C}$ until a curing age of 28 days was reached. Once fabricated, specimens were subjected to thermal conductivity, mechanical, permeability and ultrasonic pulse velocity tests. At least three samples per type of grout were tested for each property. The durability of the grouts was then evaluated by comparing the results obtained in all these tests before and after the grouts were subjected to repeated heating-cooling cycles. Also, a visual inspection of the degraded specimens was very useful for this purpose. Therefore, specimens were exposed to 28 heating-cooling cycles, each one lasting 24 hours. During the first 12 hours, specimens were submerged in a thermostatic bath at $+40^{\circ} \mathrm{C}$, while the last 12 hours where introduced in a water tank placed in a cooler at $+5^{\circ} \mathrm{C}$. 
Thermal conductivity of water-saturated grouts (at ambient pressure) was measured at 0,7 , 14, 21 and 28 cycles according to the ASTM 5334-08 [28]. For this aim, the Hukseflux TPSYS02 system together with the TP02 thermal needle was employed. Cylindrical in shape specimens, $200 \mathrm{~mm}$ high and $67 \mathrm{~mm}$ diameter solid cross section, were used. A very thin hollow stainless steel pipe was placed within the specimens so that the thermal needle could be inserted. Three tests were performed per sample and the thermal conductivity was determined as the mean value of the individual results.

Mechanical properties of the hardened grouts were evaluated at 0 and 28 cycles by means of compressive and flexural tests as defined in UNE-EN 1015-11:2000/A1. Rectangular in shape specimens, $160 \mathrm{~mm}$ long and $40 \times 40 \mathrm{~mm}^{2}$ square cross section, were used for these tests. Flexural strength was determined as the mean of the three specimens tested, while compressive strength was calculated as the mean of the six specimens tested. Since the grouts here tested lack structural purpose, values of mechanical strength are indirect indicators of the potential rise of cracks within the specimens after the heating-cooling cycles.

In this sense, ultrasonic pulse velocity tests were also developed at 0 and 28 cycles to nondestructively monitor potential degradation in the form of cracks or manufacturing defects. The test consisted of measuring the time employed for an ultrasonic pulse to cover the distance between two transducers placed at opposite faces of the specimen. Thus, if the pulse velocity in recently manufactured grouts is known, a velocity attenuation might be attributed to an alteration in their initial quality due to the cycles. The CSI Concrete Tester CCT-4 was used and the propagation time was calculated as the mean value of two measurements taken at two different points.

Finally, the hydraulic conductivity of the grout-pipe system was measured at $0,7,14,21$ and 28 cycles as an indirect indicator of grout shrinkage and loss of grout-pipe bond quality due to the different coefficient of thermal expansion of grout and pipe. The presence of defects in the form of pathways within the grout-pipe interface might result in the decrease of the GSHP 
performance and lead to environmental problems such as the connection between aquifers.

For this aim, a new device was built (Figure 4) that allowed the development of variable head permeability tests on grout-pipe (GP) specimens. The main elements of this device were: a cylindrical in shape grout specimen with hollow circular cross section, $110 \mathrm{~mm}$ high, $90 \mathrm{~mm}$ exterior diameter and $32 \mathrm{~mm}$ inner diameter; a PVC mould to keep the grout confined; a polyethylene (HDPE) pipe $32 \mathrm{~mm}$ exterior diameter and $2.4 \mathrm{~mm}$ thick; a lid to cover the pipe and avoid the water flow through it; a PMMA pipe with two marks, glued to a PVC lid, for supplying the water column. The interface between the grout and the PVC mould was sealed with silicone so that flow was restricted to either the grout or the grout-pipe interface.

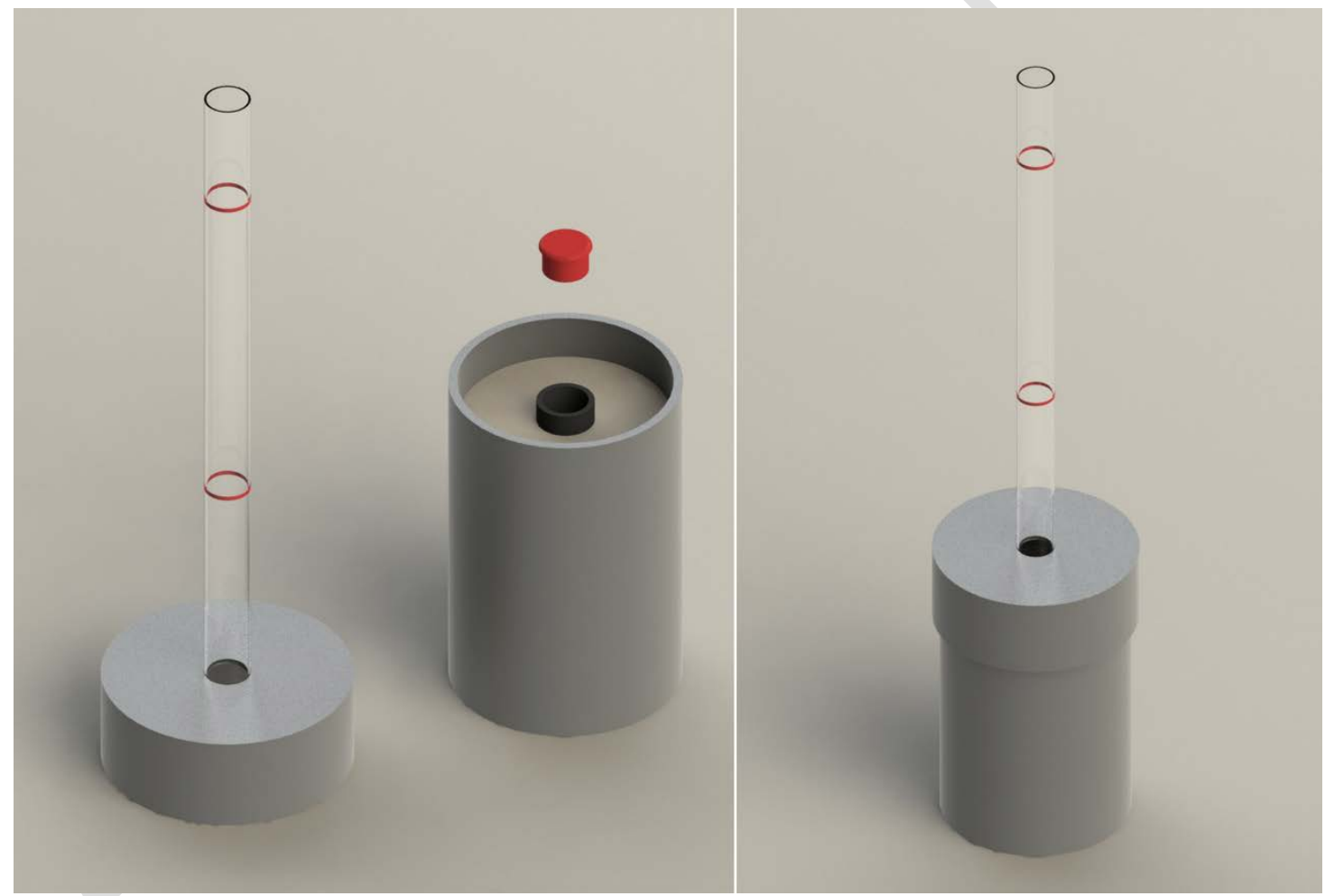

Fig. 4 - Device for measuring the variable head permeability on grout-pipe specimens.

Once the PMMA pipe was filled with water up to the top mark, the hydraulic conductivity of each type of grout was estimated based on the time needed for the water head to drop a certain length. The actual value of the hydraulic conductivity was calculated with the following expression (1): 


$$
K=\frac{V \cdot L}{\left(h_{0}-h\right) \cdot A \cdot t} \cdot \operatorname{Ln} \frac{h_{0}}{h}
$$

Where, $K$ is the hydraulic conductivity $(\mathrm{m} / \mathrm{s}) ; V$ is the volume of water that passed through the specimen $\left(\mathrm{m}^{3}\right) ; L$ is the sample length $(\mathrm{m}) ; h_{0}$ is the initial height of the water column $(\mathrm{m}) ; h$ is the final height of the water column (m); $A$ is the specimen's cross section $\left(\mathrm{m}^{2}\right)$; and $t$ is the total time for discharge (s).

Three grout-pipe specimens per type of grout were tested. On the other hand, at 28 cycles, another measurement was made after sealing the interface between the HDPE pipe and the grout in such a way that the flow was restricted only to the grout. In this case, the results would evaluate the decrease of grout quality due to the heating-cooling cycles suffered.

\section{Results and Discussion}

\section{Thermal conductivity}

Results of the thermal conductivity tests done to the selected grouts after the curing period and just before they were subjected to the heating-cooling loads ( $\mathrm{t}=0$ cycles) are displayed in Table 2. At first glance, the low densities in general, and the poor thermal properties of the bentonite in particular, seems to affect the conductivities of the grouts, that are slightly lower than those measured in more conventional cement-based mortars [12]. Actually, for the four grouts containing cement, a conductive filler (sand or graphite) and bentonite, the combined effect of the excess mixing water and the employ of bentonite result to have the largest effect on their thermal conductivity.

Table 2 - Thermal conductivity values of the tested grouts at $\mathrm{t}=0$ cycles.

\begin{tabular}{cccccc}
\hline \hline GROUT & G1 & G2 & G3 & G4 & G5 \\
\hline \hline $\begin{array}{c}\text { Thermal } \\
\text { Conductivity } \\
(\mathbf{W} / \mathrm{m} \cdot \mathrm{K})\end{array}$ & $1.59 \pm 0.02$ & $1.59 \pm 0.01$ & $1.42 \pm 0.02$ & $1.38 \pm 0.03$ & $1.64 \pm 0.01$ \\
\hline \hline
\end{tabular}


In Figure 5 the fitted curve shows the decrease of the conductivity as the amount of bentonite raises. In this case, the relation between thermal conductivity and water content is not that (graphically) evident due to the modifying effect of the large amount of graphite added to G2.

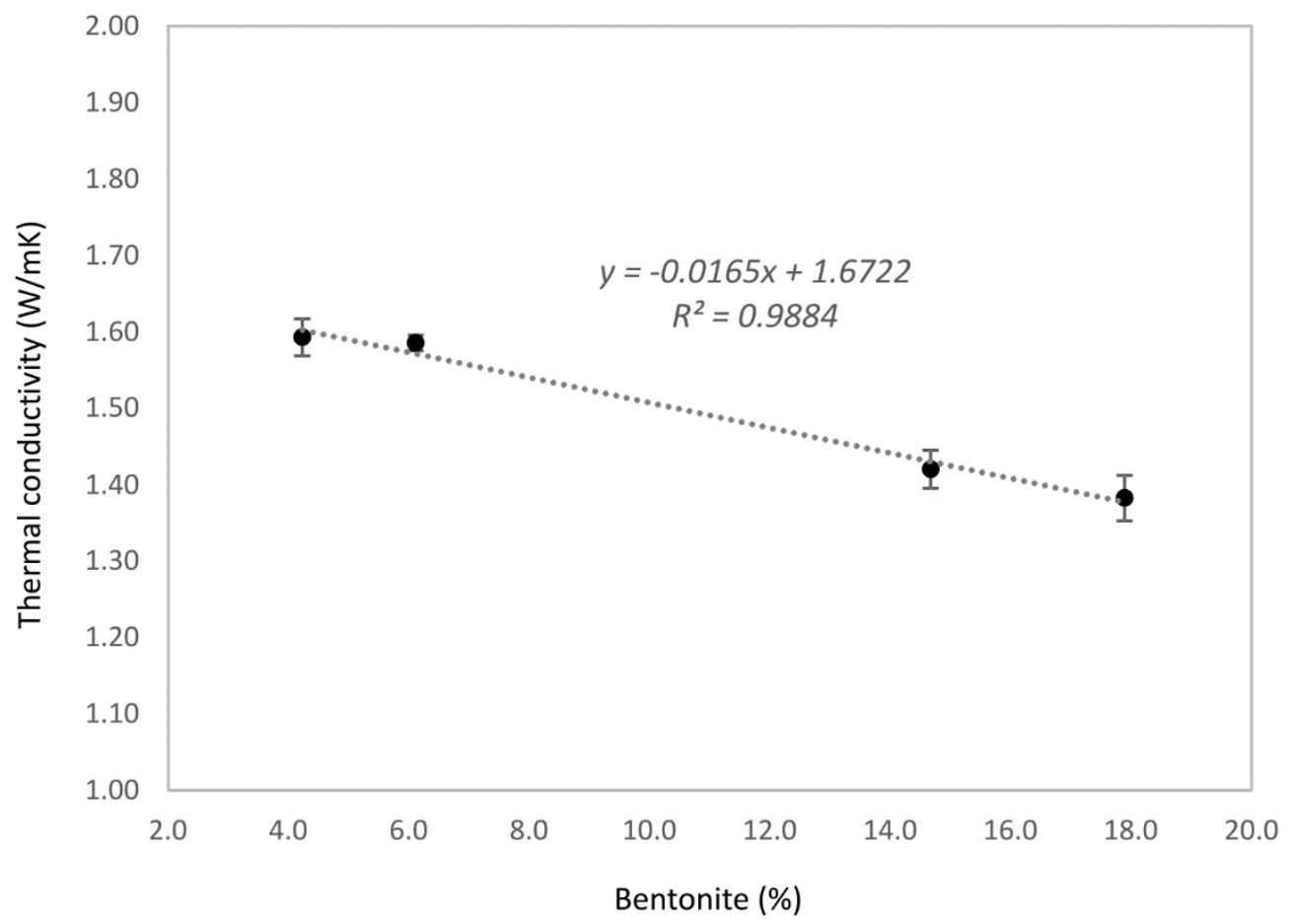

Fig. 5 - Influence of the bentonite content on the thermal conductivity of the grouts.

In any case, thermal conductivities are not as high as expected $[8,9,11]$ even for those grouts with higher amounts of silica sand and/or graphite. The reason is assumed to be that the high water/solid ratios used for workability and hence, commercially purposes, also result in higher accessible porosities, lower densities and, eventually in lower thermal conductivities of grouts and mortars [6,22] even if the use of conductive fillers is extensive. Grout $G 2$ is a particular case since a significant quantity of graphite has been incorporated to the mixture that absorbs large amount of water (Table 1). For this reason, a very low hardened density was achieved that made it not possible to obtain the expected thermal conductivity values. But even if conductivities have been sacrificed as compared to the thermally-enhanced mortars, the grouts here tested still possess suitable thermal properties while comply with the required 
workability (pumpability) attributes.

Regarding the durability of the grouts, Figure 6 shows the evolution of their thermal conductivity with time. The soft consistency of G5 didn't allow it to be subjected to the durability assessment and so conductivity with time couldn't be obtained. For the rest of them, results reveal that the grouting material is not affected at all by the heating and cooling cycles. Apparently, the thermal loads applied have not been severe enough as to cause fractures that influence the thermal properties of the grouts. A visual inspection confirmed the lack of any damage within the specimens.

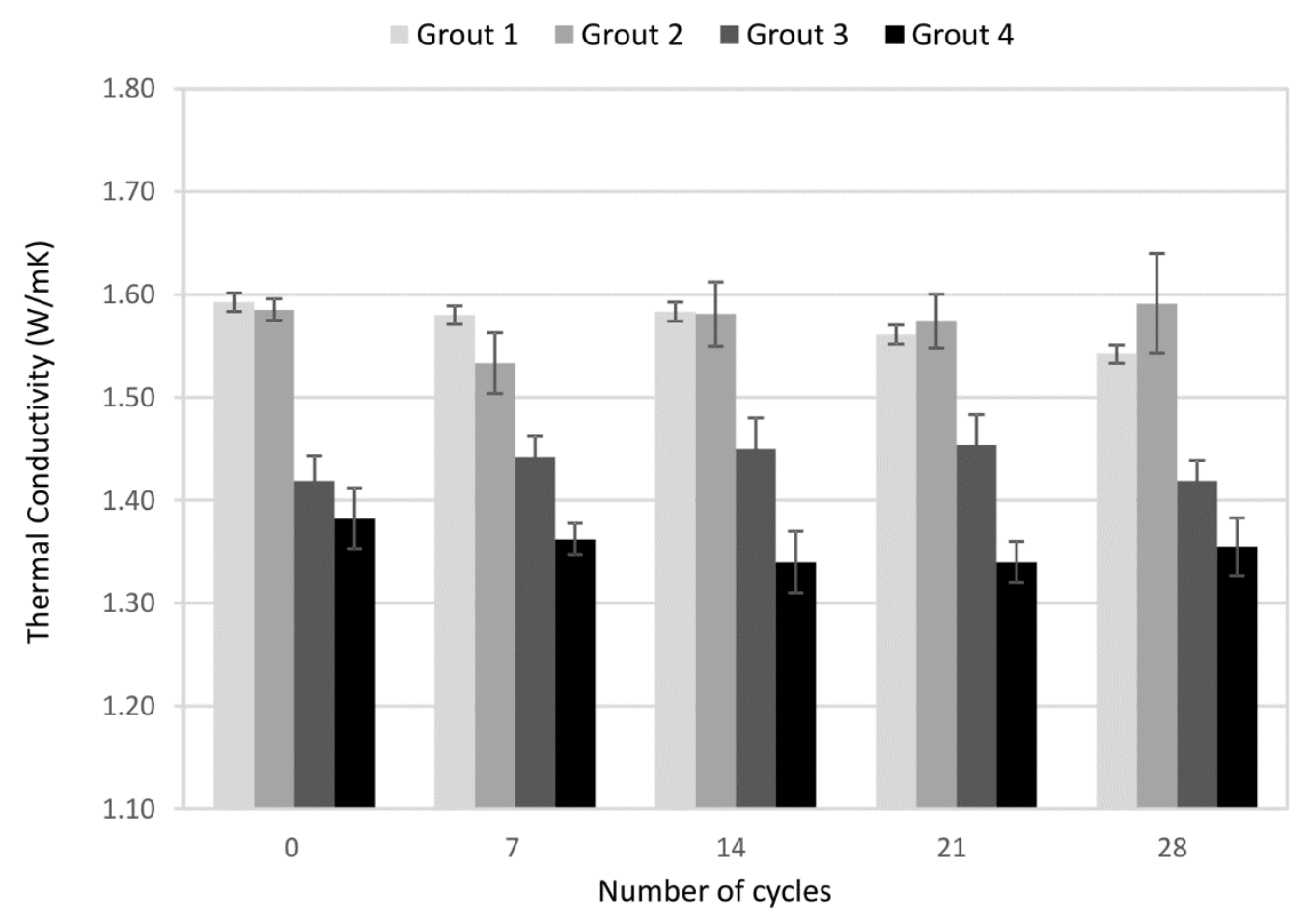

Fig. 6 - Evolution of the thermal conductivity of grouts with the thermal treatment time.

\section{Mechanical strength}

Results of mechanical tests on the four hardened grouts mainly composed of ordinary cement, bentonite and sand are presented in Figure 7 . These tests could not be done with the bentonite and sand mortar (G5) due to its extremely soft consistency, thus considering negligible its 
compressive and flexural strength. For the rest of the mortars, compressive strengths obtained before the thermal treatment were within the range of those obtained by Erol and François $[10,11]$, whereas they were low or very low as compared to more typical cement-based mortars $[17,21]$.

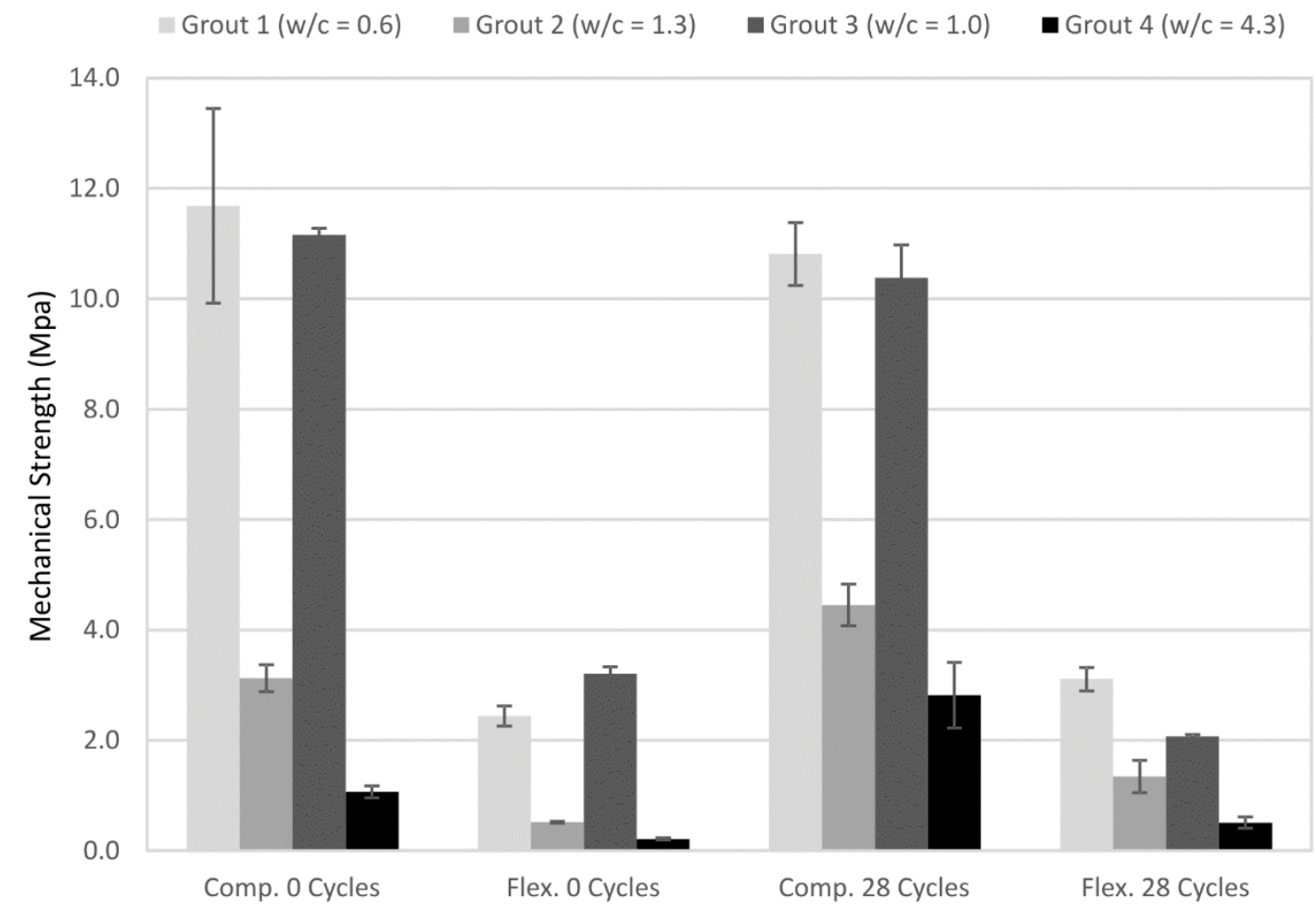

Fig. 7 - Influence of the mixing water on the mechanical strength after 28 heating-cooling cycles.

As shown in Figure 7, both compressive and flexural strengths decrease as the water/solid ratio increases, as might be expected. The water/cement (w/c) ratio is especially important when the mechanical performance is concerned. Actually, the two highest values for compressive strength were obtained for the grouts with the lowest water/cement ratios. As for the results of thermal conductivity, G2 is an exception due to the extensive use of graphite powder. So, even with a high cement content, the low hardened density of the resulting mortar due to the low density of the graphite itself and the high amount of water seem to be the cause of the low values of compressive and flexural strength. 
Therefore, the irrelevant mechanical behaviour of all the grouts here tested is clearly associated with the increasing porosity acquired by the mortar as a result of the increasing water/solid ratios used for workability purposes. However, this property is not of great importance for geothermal heat pumps applications, otherwise other cement mortars with better mechanical properties should be used $[17,21]$. All the same, it is actually a suitable indirect method for measuring the potential rise of internal and external cracks due to thermal loads. In this sense, Figure 7 also shows the values of compressive and flexural strength of the grout samples right after the 28 heating and cooling cycles were finished. As shown in the graph, results are very similar to those at $t=0$, just after the 28 days curing period was concluded and before the durability tests. Note also that grouts with the highest water/solid ratios, they even slightly increased their resistance. However, the deviation was so small that rigorous conclusions cannot be drawn based on the accuracy of the testing machine, mainly used for denser cement mortars or concretes.

Despite small deviations, no significant variation was noticed in the mechanical strength of the mortars as a consequence of the thermal treatment. No cracks able to weaken the structural integrity of the grouting material were generated, and only some very small surface fissures were found by visual inspection that did not cause changes.

A similar diagnosis might be done from the results of the ultrasonic pulse velocity tests (Figure 8). According to the decreasing values of velocity, the water employed for mixing the grout and hence, the associated porosity, is a significant parameter when manufacturing these type of highly workable mortars. On the other hand, the very small variations ( $3 \%$ on average) obtained when comparing the ultrasonic pulse velocities before and after the heating and cooling loads were applied to the specimens (Figure 8) are not significant at all if the accuracy of the testing device is considered. 


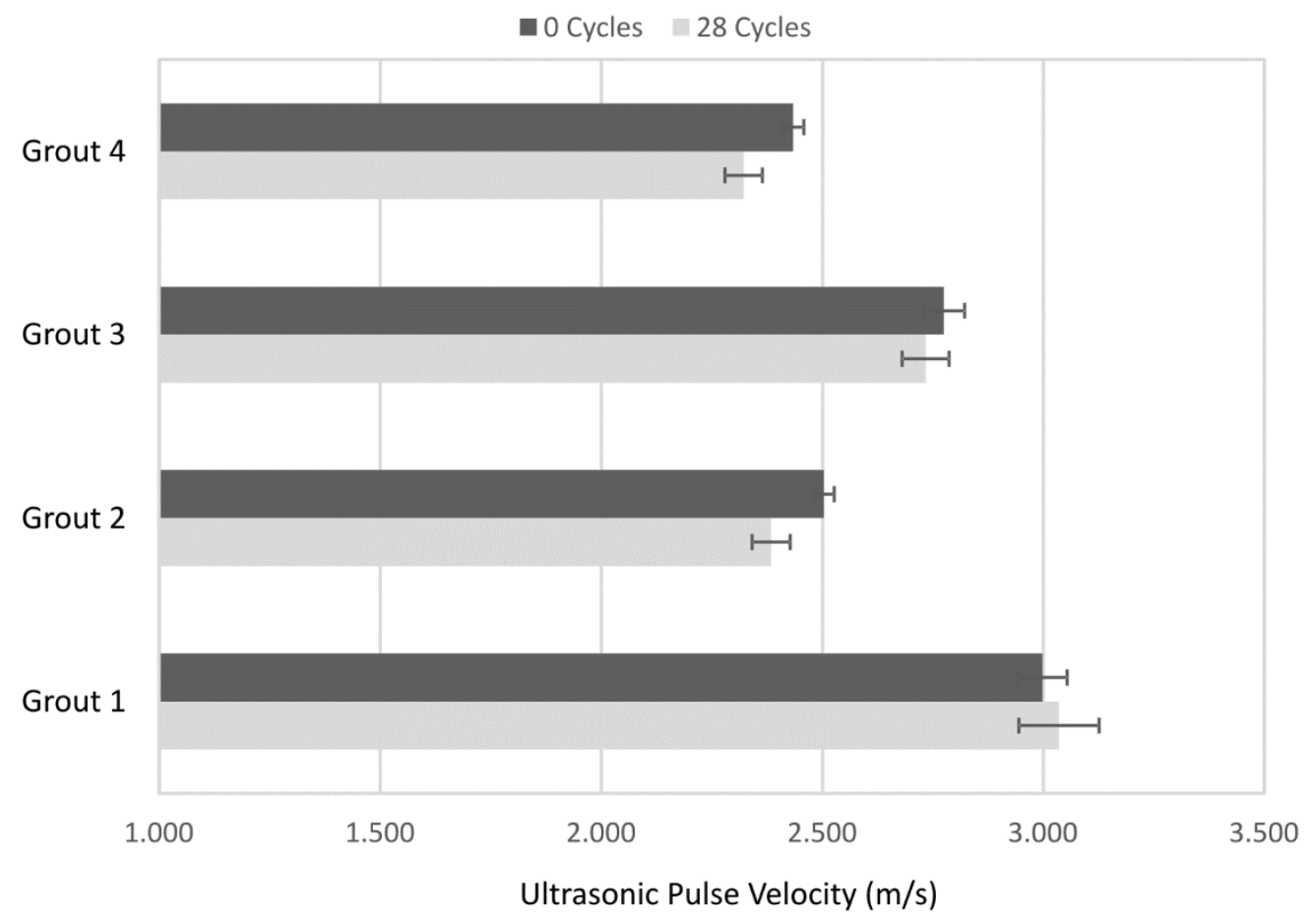

Fig. 8 - Evolution of the ultrasonic pulse velocity of grouts with the thermal treatment time.

\section{Hydraulic conductivity}

Finally, the hydraulic conductivity (permeability) of the grout-pipe specimens was measured according to the methodology described above. Results obtained right after the 28 days curing period was concluded are shown in Table 3. As it can be seen, the values of permeability are very low for all the grout-pipe specimens, especially if the use of high water/solid is taken into account. Results are very close (although slightly higher) to those obtained in [22] or are even lower to the hydraulic conductivity values obtained in [13], [16] and [17] for the grout-pipe specimens, even if the existing differences in the methodology followed is considered.

Table 3 - Hydraulic conductivity values of the tested grout-pipe specimens at $\mathrm{t}=0$ cycles.

\begin{tabular}{cccccc}
\hline \hline GROUT-PIPE & GP1 & GP2 & GP3 & GP4 & GP5 \\
\hline \hline Hydraulic & $2.5 \mathrm{E}-10$ & $6.9 \mathrm{E}-10$ & $2.9 \mathrm{E}-10$ & $4.8 \mathrm{E}-10$ & $3.4 \mathrm{E}-10$ \\
$\begin{array}{c}\text { Conductivity } \\
(\mathrm{m} / \mathbf{s})\end{array}$ & $\pm 1.2 \mathrm{E}-10$ & $\pm 1.1 \mathrm{E}-10$ & $\pm 8.5 \mathrm{E}-11$ & $\pm 1.6 \mathrm{E}-10$ & $\pm 9.3 \mathrm{E}-11$ \\
\hline \hline
\end{tabular}


At first glance, it seems that there exist a clear relation between the amount of water used for mixing the grouts and their hydraulic conductivity (Figure 9). The cause of this might be, as in previous tests, the increasing accessible porosity of the grouts. However, this cannot be guaranteed at this point because of two reasons: the very small differences found in the permeability of the four grouts as opposed to the not so high precision of the test; and more importantly, the fact that these tests measure the overall hydraulic conductivity of the groutpipe specimens, which makes it not possible to neglect the influence of the grout-pipe interface.

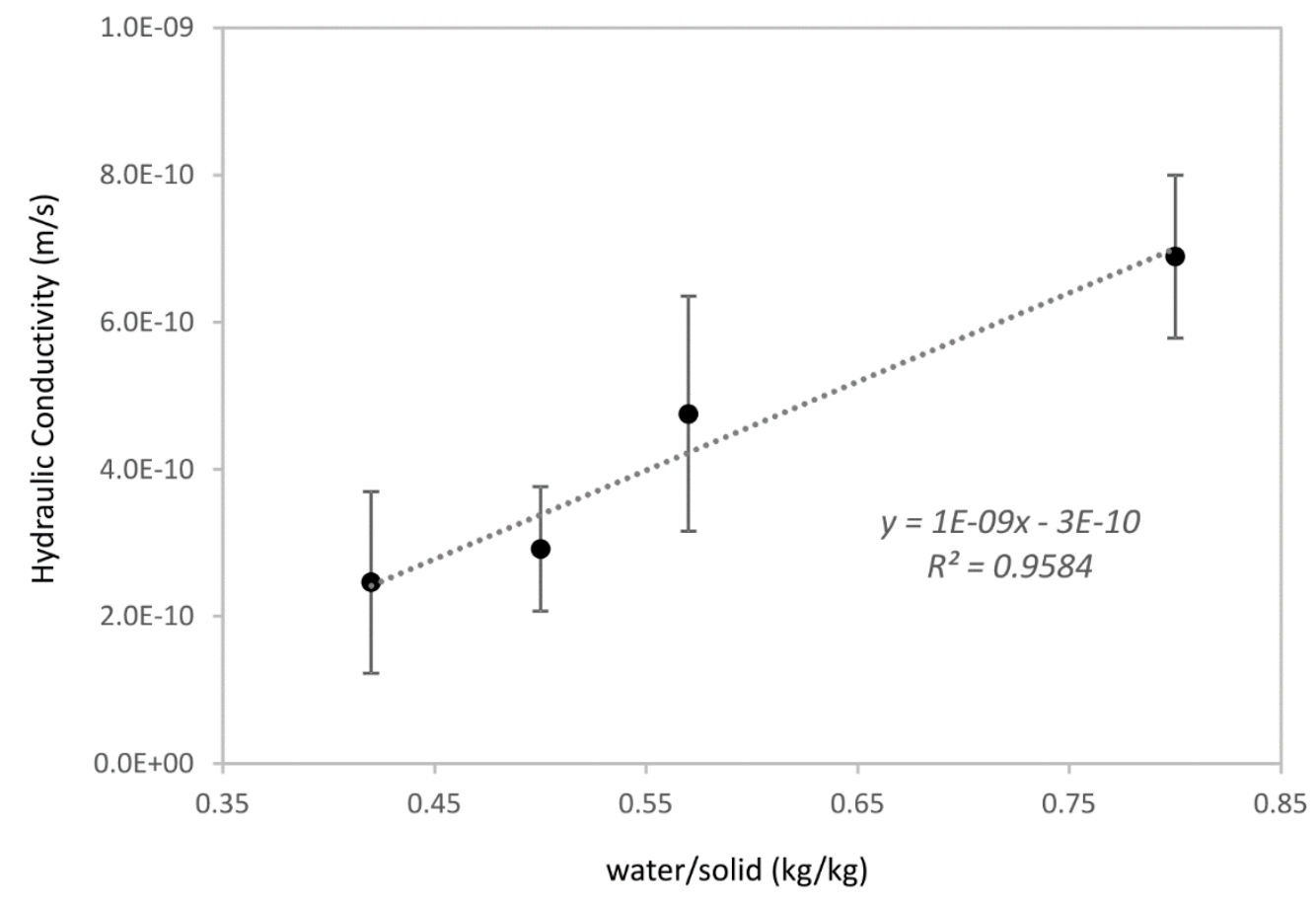

Fig. 9 - Influence of the mixing water on the permeability of the grout-pipe specimens.

As for the treatment to indirectly evaluate the influence of the thermal loads on the grout-pipe bond quality, values of hydraulic conductivity after 7, 14, 21 and 28 cycles are displayed in Figure 10. Overall, there is a certain change in the hydraulic conductivity of the grouts with the cycles that might have happened due to the different expansion and contraction coefficients of 
the HDPE pipe and the corresponding changes in dimensions at the grout-pipe interface, leading to a decrease in the bond quality [4]. The values obtained at the end of the thermal treatment are indeed higher than expected according to the results prior to the treatment. They are actually significantly higher than those obtained in [13], [16], [17] and [22]. But in spite of this significant increase of the specimens' permeability, they remained of the order of $10-7 \mathrm{~m} / \mathrm{s}$, which proved that the grout-pipe bond of the specimens was not seriously affected and that they are still suitable for providing the requirements of a geothermal heat pump installation.

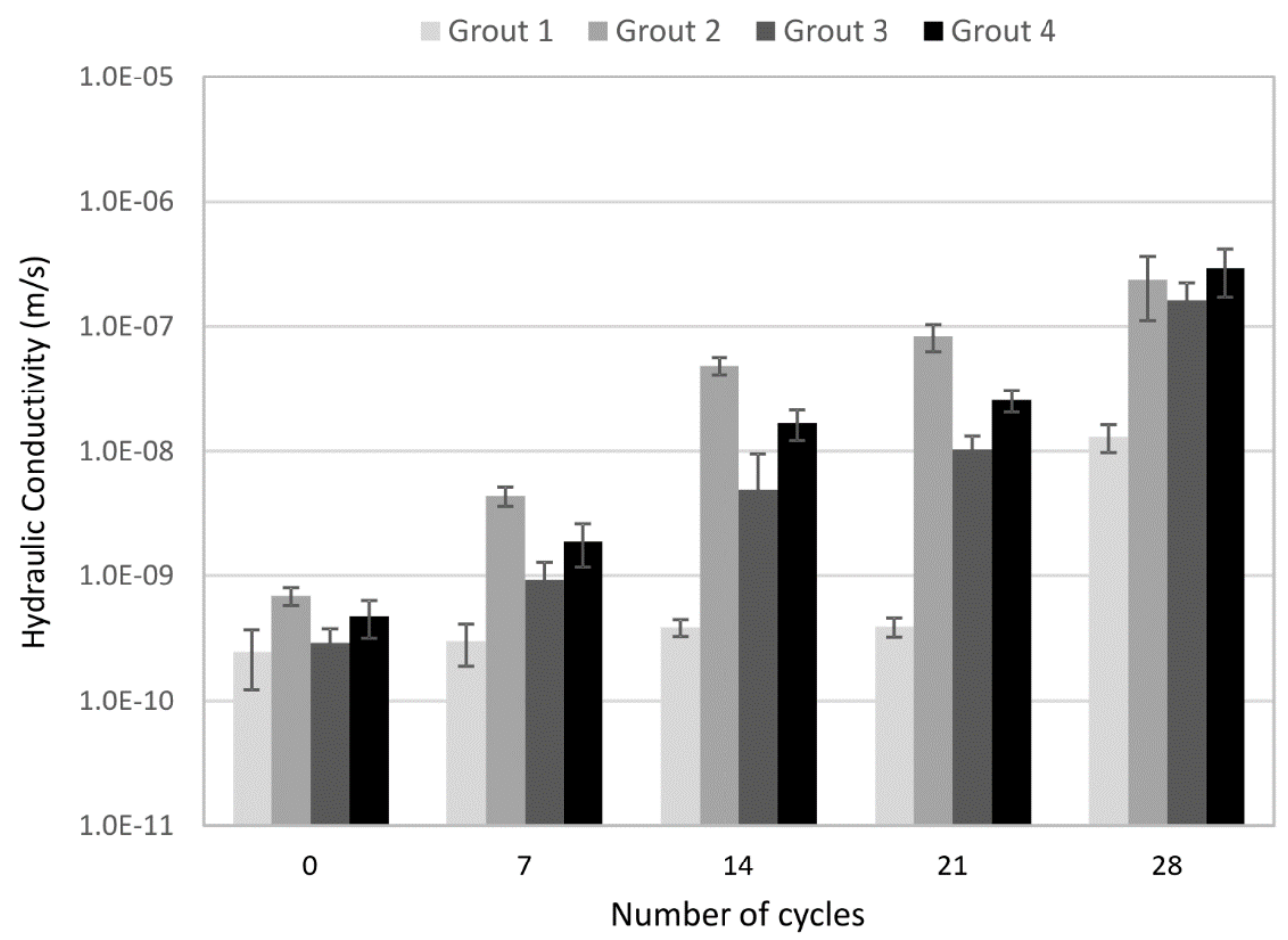

Fig. 10 - Evolution of the hydraulic conductivity of grouts with the thermal treatment time.

On the other hand, specimens GP2, GP3 and GP4 reached similar values of hydraulic conductivity at the end of the treatment, whereas GP1 reached a permeability more than ten times lower. Besides, the fact that the successive values of hydraulic conductivity obtained for GP1 were always lower than for the other, reveals the importance of the water/cement ratio (Figure 7) for the sealing performance. 
To make clear whether the increase of permeability was due to the damage in the grouting material itself or to the loss of adherence between grout and pipe, a new permeability test was carried out in agreement with the same procedure but in which the grout-pipe interface of all the specimens was sealed. Results obtained in these tests (Figure 11) clearly show how most of the permeability is recovered, thus meaning that the increase of the hydraulic conductivity mainly comes from the decrease of the bond quality, whereas the rise of important cracks and/or fissures in the material itself affect only to a minor extent. A visual inspection of the specimens (Figure 12) helped to confirm that only surface fissures arose after completing the 28 cycles of the durability treatment.

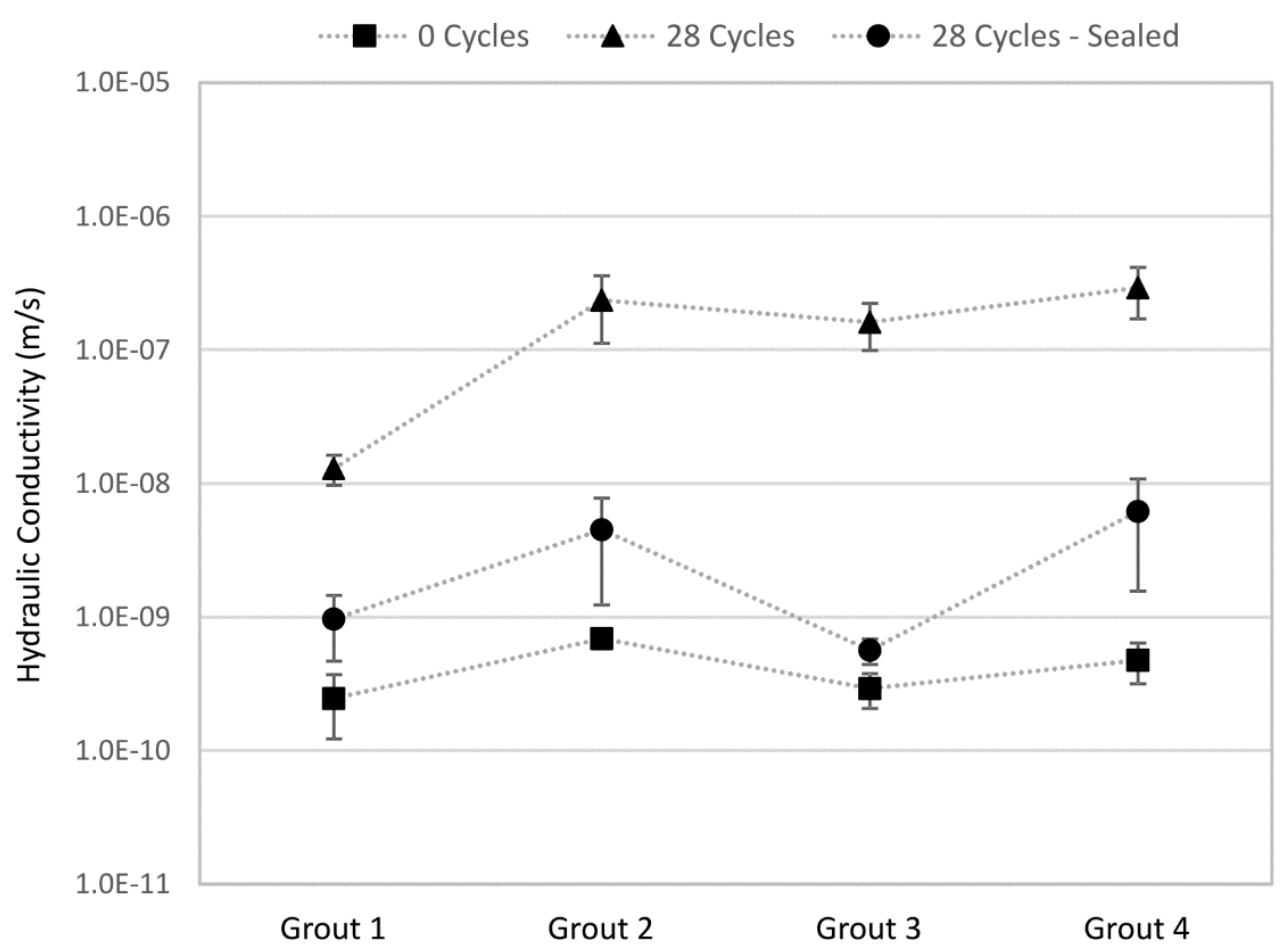

Fig. 11 - Evolution of the permeability with the treatment time when the grout-pipe interface is sealed. 

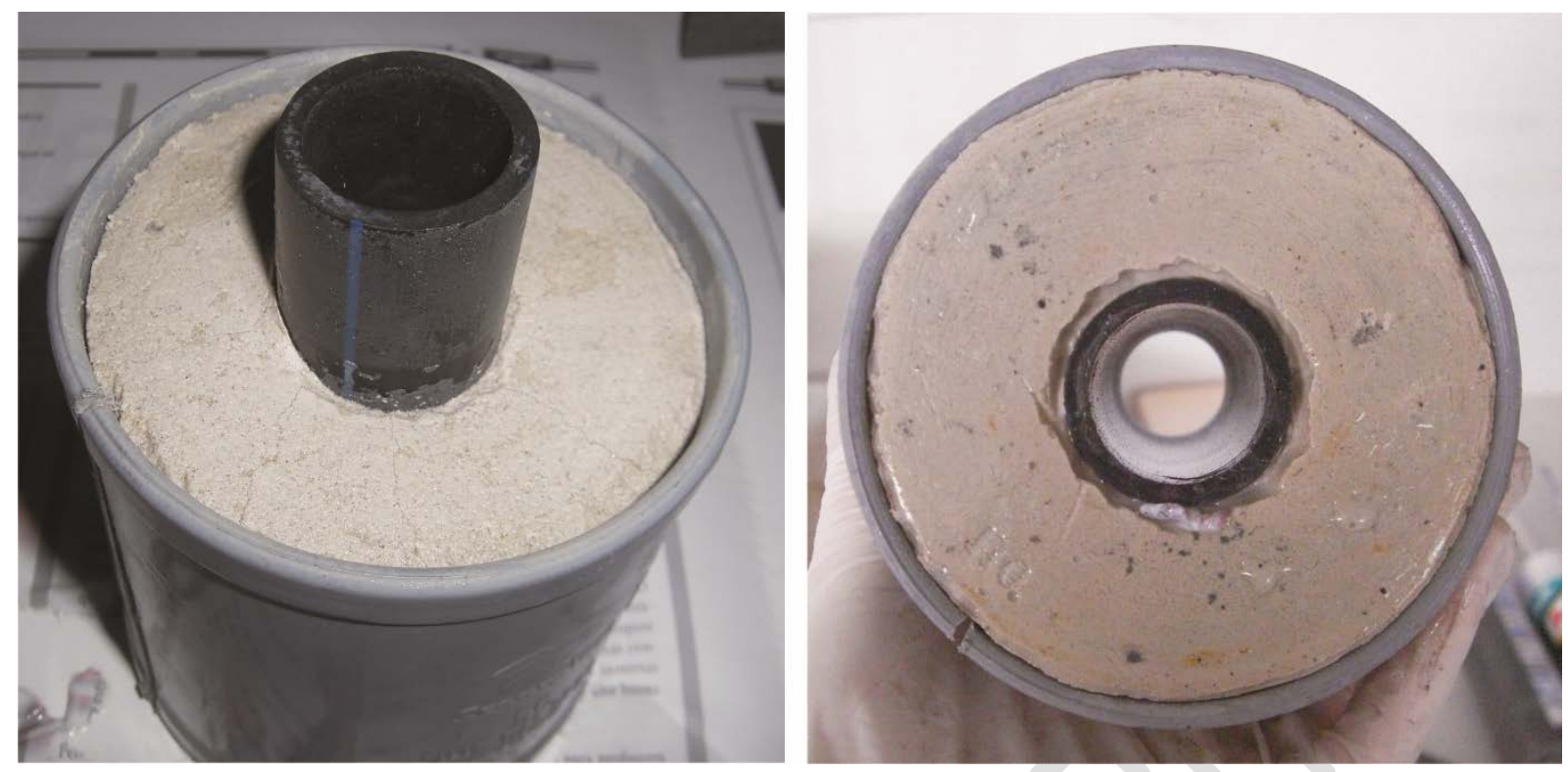

Fig. 12 - View of the grout-pipe specimen after 28 heating-cooling cycles.

\section{Conclusions}

In this paper, five different highly workable grouting materials, four of which were mainly made up of cement, sand and bentonite, were characterized and subjected to mechanical, thermal and permeability tests before and after completing 28 cycles of thermal treatment in order to verify their suitability as backfilling material in geothermal heat pumps installations.

As a result of this research, the following conclusions can be drawn:

- There exist a clear relation between the water/solid ratio of the grouts tested and all the parameters measured in this paper. Thus, the overall permeability of the grout-pipe system, the compressive and flexural strength, and the thermal conductivity of the grouting materials are affected, in greater or lesser extent, by the amount of water used for their manufacturing.

- The values of mechanical strength and thermal conductivity measured for all the grouts tested in this paper were low to medium, probably due to the amount of water used for workability purposes. The thermal treatment applied for evaluating their durability 
resulted in a lack of influence of the heating and cooling loads on the thermal and mechanical performance of the grouting materials, showing the samples no sign of important cracks or fissures after the treatment. This make them valid for ground source heat pump boreholes, especially for those placed in soils with low to medium values of thermal conductivity.

- The permeability obtained for the four different grout-pipe specimens was very low, meaning that proper sealing performance of the material and grout-pipe bond quality were achieved. On the other hand, no definite conclusions could be drawn with respect to the hydraulic conductivity of the grouting materials themselves.

- Although the thermal treatment to which the grout-pipe specimens were subjected led to an evident increase of the measured hydraulic conductivity due to a loss of quality of the grout-pipe bond, the remaining permeability confirms the applicability of the grouts, especially when the hydrogeology shows that a low risk of environmental impact exists because of a potential aquifer connection.

Therefore, in spite of the significant amount of mixing water used for workability purposes, the results of the characterization and durability tests carried out confirm the suitability of the grouts for their use in most of the conventional geothermal heat pump installations.

\section{Acknowledgements}

The authors wish to express their gratitude to the Ministerio de Economía y Competitividad which funded this study within the Spanish National Plan for Scientific and Technical Research and Innovation (INNPACTO program) through the research project IPT-2011-0877-920000. The authors are also grateful to all the organizations and companies participating in this project: Sacyr Industrial, Universidad Politécnica de Madrid and Cype.

\section{References}

[1] Omer, A.M. Energy and Environment: Applications and Sustainable Development. British 
Journal of Environment \& Climate Change, 2011, 1(4): 118-158.

[2] Directorate-General for the Environment. European Commission. Attitudes of European citizens towards the environment. Special Eurobarometer 365, 2011.

[3] Jun, L., Xu, Z., Jun, G. and Jie, Y. Evaluation of heat exchange rate of GHE in geothermal heat pump systems. Renewable Energy, 2009, 34 (12), pp. 2898-2904.

[4] Allan, M.L. Materials characterization of superplasticized cement-sand grout. Cement and Concrete Research, 2000, 30 (6), pp. 937-942.

[5] Redmund, C.P. and Lund, J.T. Thermal enhancement of bentonite grouts for vertical GSHP systems. American Society of Mechanical Engineers, Advanced Energy Systems Division, 1993, AES 29, pp. 95-106.

[6] Allan, M.L. Preliminary study on improvement of cementitious grout thermal conductivity for geothermal heat pump applications. Department of Applied Science, Brookhaven National Laboratory, New York, 1996.

[7] Smith, M.D.; Perry, R.L. Borehole grouting: Field studies and thermal performance testing. ASHRAE Transactions. 1999, 105, 451-457.

[8] Lee, C., Lee, K., Choi, H. and Choi, H.-P. Characteristics of thermally-enhanced bentonite grouts for geothermal heat exchanger in South Korea. Science China Technological Sciences, 2010, 53 (1), pp. 123-128.

[9] Delaleux, F., Py, X., Olives, R. and Dominguez, A. Enhancement of geothermal borehole heat exchangers performances by improvement of bentonite grouts conductivity. Applied Thermal Engineering, 2012, 33-34 (1), pp. 92-99.

[10] Erol, S. and François, B. Thermal, hydraulic and mechanical performances of enhanced grouting materials for borehole heat exchanger. Coupled Phenomena in Environmental 
Geotechnics - Proceedings of the International Symposium, ISSMGE TC 215, 2013, pp. 491499.

[11] Erol, S. and François, B. Efficiency of various grouting materials for borehole heat exchangers. Applied Thermal Engineering, 2014, 70 (1), pp. 788-799.

[12] Allan, M.L. Thermal conductivity of cementitious grouts for geothermal heat pumps. Progress Report FY 1997. Department of Applied Science, Brookhaven National Laboratory, New York, 1997.

[13] Allan, M.L. and Philippacopoulos, A.J. Thermally conductive cementitious grouts for geothermal heat pumps. Progress Report FY 1998. Department of Applied Science, Brookhaven National Laboratory, New York, 1998.

[14] Allan, M.L. and Philippacopoulos, A.J. Properties and performance of cement-based grouts for geothermal heat pump applications. Final Report FY 1999. Department of Applied Science, Brookhaven National Laboratory, New York, 1999.

[15] Allan, M.L. and Kavanaugh, S.P. Thermal conductivity of cementitious grouts and impact on heat exchanger length design for ground source heat pumps. HVAC\&R Research, 1999, 5 (2), pp. 87-98.

[16] Allan, M.L. and Philippacopoulos, A.J. Ground water protection issues with geothermal heat pumps. Geothermal Resources Council Transactions, 1999, 23, pp. 101-105.

[17] Allan, M.L. Materials characterization of superplasticized cement-sand grout. Cement and Concrete Research, 2000, 30 (6), pp. 937-942.

[18] Allan, M.L. and Philippacopoulos, A.J. Performance characteristics and modelling of cementitious grouts for geothermal heat pumps. Proceedings World Geothermal Congress 2000, Kyushu - Tohoku, Japan. 
[19] Philippacopoulos, A.J. and Berndt, M.L. Influence of debonding in ground heat exchangers used with geothermal heat pumps. Geothermics, 2001, 30 (5), pp. 527-545.

[20] Berndt, M.L. Strength and permeability of steel fibre reinforced grouts. Construction and building materials, 2010, 24 (9), pp. 1768-1772.

[21] Borinaga-Treviño, R., Pascual-Muñoz, P., Castro-Fresno, D. and Del Coz-Díaz, J.J. Study of different grouting materials used in vertical geothermal closed-loop heat exchangers. Applied Thermal Engineering, 2013, 50 (1), pp. 159-167.

[22] Park, M., Min, S., Lim, J., Choi, J.M. and Choi, H. Applicability of cement-based grout for ground heat exchanger considering heating-cooling cycles. Science China Technological Sciences, 2011, 54 (7), pp. 1661-1667.

[23] Borinaga-Treviño, R., Pascual-Muñoz, P., Calzada-Pérez, M.A. and Castro-Fresno, D. Freeze-thaw durability of cement-based geothermal grouting materials. Construction and building materials, 2014, 55 (1), pp. 390-397.

[24] UNE-EN 1015-6. Methods of tests for mortar for masonry. Part 6: Determination of bulk density of fresh mortar. 1999.

[25] UNE-EN 1015-10:2000/A1. Methods of tests for mortar for masonry. Part 10: Determination of dry bulk density of hardened mortar. 2007.

[26] ASTM D6910/D6910M - 09. Standard Test Method for Marsh Funnel Viscosity of Clay Construction Slurries. 2009.

[27] ASTM C940-10a. Standard Test Method for Expansion and Bleeding of Freshly Mixed Grouts for Preplaced-Aggregate Concrete in the Laboratory. 2010.

[28] UNE-EN 1015-11:2000/A1. Methods of test for mortar for masonry - Part 11: Determination of flexural and compressive strength of hardened mortar. 2007. 